\title{
The Berne Convention: the continued relevance of an ancient text
}

\author{
SAM RICKETSON*
}

A love of history has always enlivened the legal scholarship of Bill Cornish. He has written and lectured on many topics, from the role of the jury, the law of restitution and across the spectrum of intellectual property law, but one is left with the impression that his first love has always been legal history, with a strong emphasis on economic and social developments. Hence, it is appropriate in this essay to take a historical starting point, and to consider the continuing contemporary relevance of an international convention that was first formulated in the century before last. This is the Berne Convention for the Protection of Literary and Artistic Works, which is one of the fundamental cornerstones of the modern intellectual property system. There are many issues here that are ripe for consideration, and any comprehensive examination of them is beyond the scope of this essay. However, there are several matters concerned with treaty interpretation that are now of considerable significance, illustrating the continuing relevance of an 'ancient text'.

Before discussing these, however, some background is required.

\section{A. A star is reborn (the comeback kid)}

For a considerable part of its existence, the Berne Convention was essentially a static instrument. Beginning modestly, and even circumspectly, it had a vigorous adolescence and early adulthood, and then entered a period of little or no growth (unlike many middle-aged adults) and even faced the threat of substantial reduction (in the period 1960-1967). Indeed, after the trauma of successive revision conferences in 1967 and 1971 where the status quo was barely maintained, the prevailing view was that there would be no more revisions of the old kind, and that it would thereafter

\footnotetext{
* University of Melbourne.
} 
remain unchanged, a kind of enduring artifact to a particular conception of authors' rights that could be taken no further in the changing circumstances of the late twentieth century. Moreover, a significang circumvery important countries of both copyreover, a significant number of bornly remained outside the Beth copyright producers and users stubformalities rule in Article 5(1). Even as alienated, perhaps, by the no Soviet Union and Chin As we all know, this were among the notable Berne non-members. 15 years or so. As anticip position has changed radically over the past to expectations it has moved steadily to remained unrevised, but contrary the modern internation steadily to centre stage as the cornerstone of which this has occurred are worth restem. The chronological steps by

\section{- In the early 1980s, the USA and other sub}

In the early 1980 s, the USA and other substantial trading nations, lack of recognition and and Japan, became concerned at the apparent property rights in a number of other of their nationals' intellectual South America Existing in other countries, notably in Asia and Berne, had little to say about intectual property conventions, including those conventions, and the rights contained in pliance with the obligations was no effective means of ensuring comcountries that were actually signatories.

- Bilateral trade actually signatories.

were actively pursued were a limited response to these problems, and pere actively pursued by the USA in a number of instances during this - A revision of the GATT (the Uruguay, were clearly more promising. - A revision of the GATT (the Uruguay Round) beginning in 1986 protime, compliance for a broader multilateral response and, for the first one of the trade disciplines to be property norms was articulated as - Not wishing to reinvent the to be pursued at the multilateral level.

ready-to-wear set of norms wheel, Berne provided negotiators with a Agreement on Trade-Related that could be incorporated into the new alsoement on Trade-Related Intellectual Property Rights (TRIPs). ${ }^{1}$ It tive and enforther Berne-plus substantive and enforcement obligations could be erected. ${ }^{2}$ Compliance with machinery of the then become a matter for the dispute resolution

${ }^{1}$ See Article 9(1), TRIPs Agreement.

2 See further Articles 10-14 and Section 2 (Civil and Administrative Procedures and Reme-
dies), TRIPs Agreement.

3 Part V, TRIPs Agreent.
- A consequence of this was that Berne compliance became an essential component of WTO membership, regardless of whether a country was a Berne member or not. However, the USA, one of the chief promoters of TRIPs but outside of Berne for its first 102 years of existence, soon recognized the anomaly of insisting upon Berne compliance while not actually being a member itself. The USA therefore joined Berne in 1989 , and was followed by a number of other major trading countries, including China (1992), the Russian Federation (1995), Republic of Korea (1996) and Indonesia (1997). There are now over 150 members of the Berne Union, and it covers virtually all the inhabited territories of the globe.

- Interpretation of Berne norms is therefore no longer a matter for national legislators and policy makers seeking to ensure compliance under their domestic laws, but effectively in isolation from each of others. It is now a matter of real multilateral concern, with the WTO dispute resolution machinery providing an effective means of achieving compliance from WTO members. This is unlike the pre-TRIPs position where the only means of achieving compliance with Berne obligations (apart from reliance upon customary international law notions of 'fundamental breach') was the theoretical right of access to the International Court of Justice under Article 33(1) of the Paris text of Berne with respect to disputes between member countries 'concerning the interpretation or application of this Convention'. This provision had never been invoked and its effectiveness under the Paris text was substantially eroded by the facility provided to members to declare that they were not bound by the jurisdiction of the court (Article 33(2)). ${ }^{4}$

- There has been no substantive revision of Berne itself, but already a significant related or associated agreement, the WIPO Copyright Treaty (the WCT) ${ }^{5}$ together with a neighbouring rights cousin (the WIPO Performances and Phonograms Treaty ${ }^{6}$ ), has been concluded to deal specifically with digital and online issues and has now come into force.

${ }^{4}$ The right of access to the International Court of Justice was introduced in Article $27 \mathrm{bis}$ of the Brussels Act of Berne and was compulsory. In its report to the Stockholm Revision Conference in 1967, Main Committee IV noted that there had not been any petition pursuant to Article $27 \mathrm{bis}$, but also noted the view expressed by some delegates that the compulsory nature of the provision may have been an 'obstacle for several countries of the Union to the ratification even of the Brussels Act'. The Committee went on to recommend that any revised version of Article 27 bis (now Article 33) should not be mandatory: Report of Main Committee IV, Stockholm Revision Conference, in 1886. Berne Convention

Centenary. 1986 (WIPO, 1986), p. 218.
${ }^{5}$ Geneva, December $1996 . \quad 6$ Geneva, December 1996. 
As an 'associated agreement' under Article 20 of Berne, this also requires full compliance with Berne norms ${ }^{7}$ and draws upon them expressly in relation to exceptions and limitations to the new rights established under it (the 'three-step test' under Article 10)

Applying a term from the entertainment industry, it can be said that the above shows that Berne has now made a 'comeback' and is even bigger and better than before. It has even attracted the excoriation of critics who, in earlier times, might have pointed pityingly to its lack of relevance 'Burn static character. Thus, one recent commentator has titled his article 'Burn Berne' and has argued forcefully, if somewhat inappropriately, for its repeal. For good or bad, Berne is now the starting point for assessing and determining international copyright obligations, and the matter of its proper interpretation is therefore of utmost importance. Two issues, in particular, arise for consideration here:

- Given that it is the base or starting point, how does Berne control and/or constrain the interpretation and application of later instruments such as TRIPs and the WCT ? This is particularly relevant in the case of the incorporated provisions, raising the question of whether a Berne provision that is incorporated into, say, the WCT can receive a different interpretation as a provision of that instrument as opposed to the interpretation that it might receive as part of Berne.

- The extent to which 'clarifications' of Berne provisions that are embodin the later instruments such as the WCT and TRIPs are constitutive, in the sense of creating new international norms or standards under Berne, or are simply declarative of what was 'already there before?

\section{B. Approaches to interpretation}

Berne is an old treaty (1886), and even its latest text (Paris, 1971) precedes the adoption of the Vienna Convention on the Law of Treaties. ${ }^{9}$ Nonetheless, it seems generally accepted that the rules on treaty interpretation contained in that instrument, in particular Articles 31-32, are codifications of the rules of customary international law on such matters.

7 See Article 1(4), WCT.

${ }^{8}$ A Story, 'Burn Berne: why the Leading International Copyright Convention must be Repealed', (2003) 40 Houston Law Review 101

${ }^{9}$ Under Article 4 of the Vienna Convention, it is provided that it only applies to treaties to the Paris text of Berne but into force (27 January 1980). Accordingly, it does not apply to the Paris text of Berne but clearly does to the WCT (entry into force 2002).
Accordingly, both the Berne Convention and the later instruments such as TRIPs ${ }^{10}$ and the WCT fall to be interpreted under the same rules. A potential point(s) of conflict, however, that arises is where the same provision, namely a provision of Berne, falls to be interpreted according to these rules, but within the context of different instruments, i.e. as part of Berne itself, as an incorporated part of the WCT, and as an incorporated part of the TRIPs Agreement. Each of these instruments was formulated in different circumstances and with different purposes, and these matters can have a significant effect on their respective interpretations. The starting point here is Article 31(1) of the Vienna Convention, which provides:

'A treaty shall be interpreted in good faith in accordance with the ordinary meaning to be given to the terms of the treaty in their context and in the light of its object and purpose.'

Leaving aside the matter of 'context' (helpfully defined in Article 31(2) as including the text of the treaty and accompanying and subsequent agreements between the parties), the exhortation to interpret 'in the light of its object and purpose' can give rise to potentially different approaches as between Berne and the later agreements.

How are the object and purpose of a treaty to be ascertained? An obvious starting point is to consider the title and preamble of the treaty in question. In the case of the latest text of Berne, the answer is, at first reading, quite straightforward: it is a 'Convention for the protection of the rights of authors in their literary and artistic works' and begins with a recital that ' $T \mathrm{~T}]$ he countries of the Union, being equally animated by the desire to protect, in as effective and uniform a manner as possible, the rights of authors in their literary and artistic works, ... have agreed as follows ...' There is no other preamble or recital of the kind so beloved of modern treaty makers and legislators, particularly in Europe, that points to any other object or purpose of the Convention. The immediate impression,

${ }^{10}$ While the TRIPs Agreement is a later agreement (1994), there is a provision in Article 3(2) of the Understanding on Dispute Settlement, to which TRIPs is subject that dispute panels are to construe TRIPS 'in accordance with the customary rules of interpretation of public international law'. It appears that the reason for this is that the USA, an important member of TRIPs, is not a party to the Vienna Convention. See further N. W. Netanel, 'The Digital Agenda of the World Intellectual Property Organization: Comment: The Next Round: The Impact of the WIPO Copyright Treaty on TRIPS Dispute Settlement' (1997) 37 Virginia Journal of International Law 441, 449. At the same time, it appears that the USA takes the view that the provisions of the Vienna Convention reflect custom: see further Restatement (Third) of the Foreign Relations Law of the United States 145 (1986). 
therefore, is of an agreement that is one-dimensional in its concerns, namely that it is directed solely to the protection of the rights of authors. In the interpretation of its provisions, therefore, it can be said that the preferred interpretation will be the one that advances this objective, as distinct from any other that might serve other purposes or even be at odds with the protection of the interests of authors.

By contrast, both TRIPs and the WCT contain a number of competing objects and purposes that are to be balanced, it seems, against those of authors. Thus, the WCT preamble starts with the rights of authors, but then lists a number of other matters that are to be taken into account:

\section{'The Contracting Parties,}

Desiring to develop and maintain the protection of the rights of authors in their literary and artistic works in a manner as effective and uniform as possible,

Recognizing the need to introduce new international rules and clarify the interpretation of certain existing rules in order to provide adequate solutions to the questions raised by new economic, social, cultural and technological developments,

Recognizing the profound impact of the development and convergence of information and communication technologies on the creation and use of literary and artistic works,

Emphasizing the outstanding significance of copyright protection as an incentive for literary and artistic creation,

Recognizing the need to maintain a balance between the rights of authors and the larger public interest, particularly education, research and access to information, as reflected in the Berne Convention,

Have agreed as follows: ... '

Some of these matters are neutral in content, e.g. the references to the introduction of new international rules and the impact of economic, social, cultural and technological developments, but the sting comes at the end: the need to 'maintain a balance' with competing public interests. In other words, authors' interests and the copyright incentive are to be moderated or weighed against these other interests.

The TRIPs Agreement is even more catholic in its preamble, with trade matters accentuated as well as the interests of developing countries and developmental and technological objectives. There is no specific reference to the importance (or otherwise) of authors and/or creators, although there is a solemn recognition that 'intellectual property rights are private rights'. However, Articles 7 and 8 have specific relevance to the matter of object and purpose. Article 7, entitled 'Objectives', raises the matter of 'balance' directly:

'The protection and enforcement of intellectual property rights should contribute to the promotion of technological innovation and to the transfer and dissemination of technology, to the mutual advantage of producers and users of technological knowledge and in a manner conducive to social and economic welfare, and to a balance of rights and obligations.'

Article 8 then articulates certain 'principles' that members may take into account in formulating and amending their laws and regulations, allowing them to adopt 'measures necessary to protect public health and nutrition, and to promote the public interest in sectors of vital importance to their socio-economic and technological development' (Article 8(1)) as well as adopting 'appropriate measures' to prevent the abuse of intellectual property rights by rights holders (Article $8(2)$ ). TRIPs is clearly an instrumentalist agreement, that sees intellectual property rights, including copyright, as means for promoting certain trade, economic and social purposes: the rights of authors here are only one aspect of the matrix of interests involved.

It will be obvious that under both the WCT and TRIPs there is a need to accommodate or 'balance' a number of objectives or purposes and that some of these may well be inconsistent, if not in conflict. Thus, where there is a choice of interpretations of a particular provision that might favour authors, in one instance, or some other interest, such as education, research, public health or development, in another, the first might be preferred under Berne with the second being preferred under the WCT or TRIPs, as the case may be.

These differences are of more than academic interest, as becomes apparent when one approaches the interpretation of a common clause such as the three-step test. The latter is replete with terms that may be interpreted in various ways, for example, the expressions 'certain special cases' (step one), 'normal exploitation of the work' (step two) and 'unreasonably prejudice' and 'legitimate interests of the author' (step three). Each may receive a wider or narrower interpretation, e.g. with respect to whether a particular kind of use of copyright material can be made subject to a compulsory licence, depending upon what objectives and purposes are in mind, and this can clearly lead to inconsistent results when one is considering whether a particular limitation or exception in national law is acceptable according to the three-step test. And this, of course, is just one 
example of the differences that may arise as between the provisions of earlier and later texts. Given that both the WCT and TRIPs incorporate the whole of Articles 1-21 of Berne, ${ }^{11}$ other issues that might arise arate follows:

- In relation to the exclusive right of reproduction under Article 9 of Berne, does this extend to digital uses and acts of storage in an electronic medium? This is a matter of some uncertainty (see below), where narrower and wider views are possible. Thus, under Berne a wider and more pro-author interpretation might suggest an affirmative answer, whereas a more limited response might follow under the WCT and TRIPs when regard is had to public interest considerations such as educational and
developmental uses.

- In relation to the broadcasting and communication rights under Articles 11 bis and 11 ter of Berne, do these cover what another contributor to this volume ${ }^{12}$ has called 'push' and 'pull' technologies? Once again, differing conclusions might follow, depending upon which instrument is under consideration.

- In the case of moral rights under Article 6bis of Berne, is the protection of these rights under the WCT (but not TRIPs) the same as under Berne? For example, issues of waiver and consent, which are not explicitly dealt with in that provision might be more readily excluded under a proauthor Berne interpretation, but might be more readily comprehended
under a more 'balanced' WCT.

- In relation to Article 18 of Berne, would the 'conditions of the application of the principle [of retroactivity]' referred to Article 18(3) permit of a more flexible application under the WCT and/or TRIPs, than under
Berne?

These are only instances of the kind of divergences that could arise in the interpretation of common provisions under these different instruments. Thus, a more pro-author interpretation under Berne may sit uneasily with a more 'balanced' interpretation under the WCT or TRIPs. This lack of conformity between objects and purposes is therefore a potential problem. Or is it?

There are two possible means by which these conflicts may be resolved. The first is to be found in express provisions of the later texts; the second

${ }^{11}$ Noting, of course, that TRIPs specifically excludes any requirement for member countries to comply with Article 6 bis of Berne, which deals with moral rights.
${ }^{12}$ See J. Ginsburg 'The (new?) right of making avalable the puts

${ }^{12}$ See J. Ginsburg 'The (new?) right of making available to the public', p. 234, infro. is by having regard more generally to the overall text and history of the earlier text.

\section{Express provisions of the later text}

In the case of the WCT, Article 1 tackles the problem directly by providing as follows:

\section{Relation to the Berne Convention}

(1) This treaty is a special agreement within the meaning of Article 20 of the Berne Convention for the Protection of Literary and Artistic Works, as regards Contracting Parties that are countries of the Union established by that Convention. This Treaty shall not have any connection with treaties other than the Berne Convention, nor shall it prejudice any rights and obligations under any other treaties.

(2) Nothing in this Treaty shall derogate from existing obligations that Contracting Parties have to each other under the Berne Convention for the Protection of Literary and Artistic Works.

(3) $\ldots$

(4) Contracting Parties shall comply with Articles 1 to 21 and the Appendix of the Berne Convention.'

These provisions apply immediate constraints on the interpretation of the WCT's provisions, including those that are incorporated from Berne. Thus, a 'special agreement' under Article 20 of Berne can grant to authors more extensive rights than those granted by the Convention, but cannot contain other provisions contrary to this Convention. More specifically, the non-derogation provision in Article 1(2) of the WCT must entail the consequence that no interpretation of a WCT provision should be adopted that would be inconsistent with the interpretation and application of an existing obligation that Berne members that are also WCT members have between themselves. Finally, Article 1(4), the incorporation provision, requires compliance with the substantive obligations of Berne, regardless of whether the states concerned are members of Berne or not.

Article 1 of the WCT therefore 'ties back' WCT obligations to those of Berne in two ways: as a special agreement, it cannot be in conflict with the earlier instrument (Article 1(1)) and, in the case of Berne members that are members of the WCT, it cannot derogate from the obligations that those members have towards each other under Berne (Article 1(2)). In the case of incorporated Berne provisions, this must mean that it is the Berne interpretation that should be applied to these provisions, even though 
they are strictly obligations under the WCT. This leaves unanswered the question of what is the position of a non-Berne WCT member - could such a country apply a different non-Berne interpretation to an incorporated Berne provision, on the basis that this will not be in breach of Article 1(2), as the country in question is not a Berne member and of no Berne obligations towards any other count a Berne member and has such a possibility math towards any other country that it can breach? But overlap to date complete verlap to date between Berne and WCT membership.

Under the TRIPs Agreement, a similar position applies: there is an identical non-derogation provision in Article 2(2), under which nothing in Parts I to IV of TRIPs is to derogate from existing obligations that members have towards each other under Berne. While this clearly indicates the primacy of Berne interpretations of incorporated Berne obligations, the may have a more wide-ranging impact than in the case of the WCT. The latter, after all, is a special agreement under Berne. The TRIPs Agreement, by contrast, seeks to achieve other and quite different purposes, and the impact of Article 2(2) must therefore be to pare back TRIPs to the extent that it is not consistent with Berne. There is an oddity that should be noted here: under Article 9(1) of TRIPs, it is provided that the obligations of members to comply with Articles 1-21 of Berne and the Appendix do not extend to rights or obligations arising under Article 6bis. Accord ingly, there can be no requirement under TRIPs to protect moral rights as such. In particular, this is reflected in the formulation of the three-step test that is adopted in Article 13, the third step of which refers to the 'legitimate interests of the right holder' as distinct from the 'legitimate interests of the author' under Article 9(2) of Berne. This indicates that an exception under Article 13 of TRIPs to an incorporated Berne right such as reproduction or public performance, could entail a consequence that was unreasonably prejudicial to the legitimate interests of authors so long as it did not have this effect on right holders (who might be quite different persons or entities). An example might be an omission to acknowledge authorship or a licence to make changes to a work without the permission of the author. However, even if such an exception could be justified in terms of Article 13, it could, in the case of Berne members, cut across their obligations under Article 6 bis of that Convention, and therefore be in breach of Article 2(2) of TRIPs (the non-derogation provision). Accordingly, while TRIPs does not require the protection of provision). by way of incorporation of Berne, it will not be possible for any provision of TRIPs to authorize the doing of something that is contrary to rights obligations that members have directly under Berne.

\section{The provisions of the earlier text}

While Articles 1(2) of the WCT and 2(2) of TRIPs peg back the requirements of that instrument to Berne interpretations, it is also possible that the objects and purposes of Berne travel some way toward the more balanced approach that is embodied in both these later instruments. Thus, it is significant to note the 'recognition' in the WCT preamble quoted above of 'the need to maintain a balance between the rights of authors and the larger public interest, particularly education, research and access to information, as reflected in the Berne Convention'. This reference may be special pleading - after all, a provision in a later text cannot on its own make the Berne Convention what it is not, namely a convention concerned with balancing the rights of authors against those of the wider public - but it does prompt a further inquiry into what is meant by the expression 'object and purpose' as it appears in Article 31(1) of the Vienna Convention. In this regard, it is useful to look beyond the words of the Berne preamble to determine what more may be said about the 'object and purpose' of the Convention. Titles and preambles do not necessarily contain the sum total here, particularly in the case of older agreements formulated before the present fashion of lengthy preambles and recitals. In the case of Berne, it is possible to make the following observations:

- The preamble of the present Paris text only dates from that text (1971): prior to this, there was no preamble at all. There is no explanation for this insertion, other than a statement in the Report of the 1971 Revision Conference that it was desired to recognize the work of the previous Stockholm Conference (which was done in the next recital after that quoted above).$^{13}$ It will be recalled that the Paris Revision Conference was something of a 'repair job', intended to resolve the divergences that had emerged at the Stockholm Conference four years earlier with respect to developed and developing countries. ${ }^{14}$ The object of delegates, therefore, was to ensure the continuity of what had gone before, but at the same time the balance of the Convention was significantly altered with the adoption of the Appendix and the recognition of the concerns of developing countries. This suggests that the apparently stark proauthor objective in the preamble needs to be interpreted in this light.

13 General Report of the Diplomatic Conference for the Revision of the Berne Convention, Paris, 5 July to 24 July 1971, para. 20.

${ }^{14}$ See further S. Ricketson, The Berne Convention for the Protection of Literary and Artistic Works: 1886-1986 (Centre for Commercial Law Studies, Queen Mary College, 1987), chapter 11 . 
- The Berne Convention, as an overall instrument, has never been limited to just the single objective of protecting authors' rights. An examination of its successive texts shows that other interests have long been recognized in its provisions, for example:

- In the 1886 text, translation rights were limited to 10 years (Article 4) and a further Article (6), while recognizing the protection of 'lawful translations' as 'original works', acknowledged that once the translation right of a work had fallen into the public domain, the translator could not 'oppose the translation of the same work by other writers'. The interests of user countries in having ready access to translations of foreign texts were clearly recognized in these provisions.

- The 1886 text also contained exceptions in relation to newspaper articles of 'political discussion' and 'news of the day' and 'miscellaneous information' (Article 7), while educational and scientific uses were stated 'not to be affected by the present Convention' (Article 8).

- The 1886 text also contained (as have all subsequent texts) a 'public order' override for sovereign states (Article 13).

- The Berlin text of 1908 retained and refined the exceptions and limitations of the original text, while expressly acknowledging the interests of the emerging sound recording industry in the compulsory mechanical reproduction licence that was included in new Article 13.

- The Rome text of 1928, while recognizing new exclusive rights in relation to broadcasting and public communication of works, also acknowledged in Article 11 bis (2) the public interest aspect of these new rights by leaving the regulation of their exercise to national legislation.

- The Brussels text continued prior exceptions and limitations and added a specific provision with respect to the reporting of current events (Article 10bis), while the 'minor reservations' doctrine was enunciated in the General Report of Marcel Plaisant as a set of implied exceptions to public performance and communication rights.

- The limitations with respect to developing countries contained in the Stockholm and Paris texts have already been referred to above.

Accordingly, the reference to 'balance' and the Berne Convention in the WCT preamble is far from meaningless, and points to the need to interpret Berne provisions in a qualified way. As Numa Droz, the Swiss president of the Berne drafting conferences of 1884-1886, stated in his closing address to the first conference in 1884, the aim of the drafters was far from absolute:
'Whereas, for one thing, certain delegations might have wished for more extensive and more uniform protection of authors' rights, due account did also have to be taken of the fact that the ideal principles whose triumph we are working towards can only progress gradually on the so-varied countries that we wish to see joining the Union. Consideration also has to be given to the fact that limitations on absolute protection are dictated, rightly in my opinion, by the public interest. The ever-growing need for mass instruction could never be met if there were no reproduction facilities which at the same time, should not generate into abuses. These were the various viewpoints and interests which we have sought to reconcile in the draft convention ... Our work is therefore the result of mutual concessions and it is with that in mind that it is recommended to all governments for approval. ${ }^{15}$

In this way, it can be said that the approaches to interpretation under Berne and later instruments such as the WCT and TRIPs are not necessarily as far apart as might at first appear. WCT and TRIPs members cannot be required to interpret their Berne obligations in any way other than as required by that Convention; on the other hand, the latter should be interpreted in accordance with the modified objects and purposes outlined above.

\section{Later 'clarifications' of Berne: the constitutive/ declarative debate}

A further issue of interpretation concerns the effect of provisions in a later text, such as the WCT or TRIPs, that seeks to indicate what is covered, or intended to be covered, by an earlier agreement, such as Berne. For present purposes, the WCT is of more immediate interest, as it contains a number of such 'clarifications', each of which is framed in a different way, for example:

1. Computer programs: Article 4 of the WCT provides that these are protected 'as literary works within the meaning of Article 2 of the Berne Convention'. It is further provided that such protection applies to 'computer programs, whatever may be the mode or form of their expression'. An 'agreed statement' then provides that the 'scope of protection for computer programs under Article 4 of this Treaty, read with Article 2,

15 Minutes of the Sixth Meeting of the Conference for the Protection of Authors' Rights, 18 September 1884 in 1886. Berne Convention Centenary. 1986 (WIPO, 1986), p. 105. 
is consistent with Article 2 of the Berne Convention and on a par with the relevant provisions of the TRIPs Agreement'.

2. Exceptions and limitations: Article 10(2) provides that Contracting Parties shall, 'when applying the Berne Convention, confine any limitations of or exceptions to rights provided for therein' in accordance with the three-step test. There is an elaborate agreed statement to this provision that seeks to 'clarify' its effect $v i s-d$-vis the Berne Convention.

3. Application in the digital environment: There is no provision in the WCT that expressly addresses the scope of the reproduction right under Article 9 of Berne, but there is the following agreed statement to
Article 1(4):

'The reproduction right, as set out in Article 9 of the Berne Convention, and the exceptions permitted thereunder, fully apply in the digital environment, in particular the use of works in digital form. It is understood that the storage of a protected work in digital form in an electronic medium constitutes a reproduction within the meaning of Article 9 of the Berne Convention.

Each of these examples involves an analysis of the relationships between different texts, as well as a consideration of the status of the various accompanying 'agreed statements', and the author has dealt at length elsewhere with the second and third. ${ }^{16}$ The following discussion is therefore limited to the first of these, computer programs.

\section{Computer programs}

At first sight, Article 2 of the WCT attempts to resolve an issue that was previously unclear under Berne, namely whether computer programs fall within the scope of the expression 'literary and artistic works' which is defined in Article 2(1) of that agreement. The latter provides inclusively that "the expression "literary and artistic works" shall include every production in the literary, scientific and artistic domain, whatever may be the mode or form of its expression . . . A list of examples then follows, but these do not include computer programs, understandably, perhaps, since Article 2(1) was last revised in 1967 (at Stockholm), and the importance of computer programs was only dimly perceived at this stage. Indeed, for some time after 1967, it was unclear whether these were more

${ }^{16}$ The author has already dealt at length with issues concerning the three-step test and digital reproduction in a study prepared for WIPO in 2003 and available at http://www.wipo.int appropriately protected under patent law or whether some intermediate sui generis solution was desirable. ${ }^{17}$ It was only by the mid-1980s that it was clear that a number of countries were adopting a copyright approach, protecting computer programs as original literary works. ${ }^{18}$ Writing in 1986 on the centenary of the Berne Convention, Dr Arpad Bogsch, the former Director-General of WIPO, noted that, although many member countries were now protecting computer programs under copyright, there were still wide differences as to the scope and form of this protection, while some countries had some doubts about this, as this would 'erode the system of protecting traditional forms of authors' works'. Dr Bogsch went on to note that at some stage the importance of this subject-matter would be such that:

... complete clarity will be indispensable about the question whether every country to the Berne Convention is obliged - because of its being party to that Convention - to grant protection (with the norms of that Convention) to computer programs and, if so, is obliged to grant such protection to computer programs created or first (or simultaneously) published in any other country member of the Berne Union. ${ }^{19}$

At this stage, therefore, Dr Bogsch was clearly of the view that Berne itself would need amendment, in order to ensure that computer programs were included as literary works. Ten years later, this development had certainly become more pronounced at the national level, and, indeed, protection of computer programs as literary works under Berne had become a mandatory requirement under the TRIPs Agreement in $1994 .^{20}$ Insertion of a similar requirement under Article 4 of the WCT was therefore a logical next step.

But do these 'collateral obligations' under the WCT and TRIPs mean that the protection of computer programs is now mandated under Article 2(1) of Berne itself, in the absence of any direct amendment to that provision? There can be no doubt that such an obligation binds members of TRIPs and the WCT as part of their wider obligations under those

17 After a study by a WIPO Advisory Group of Non-Governmental Experts on the Protection of Computer Programs, model provisions for the protection of computer programs were of Computer [1977] Industrial proposed by
Property 265.

${ }_{18}$ A notable first was the USA, then not a Berne member, that did so in 1980; Australia followed in 1984; the European Union in 1991, with the adoption of the Council Directive $91 / 250 / \mathrm{EEC}$ of 14 May 1991 on the legal protection of computer programs.

19 1886. Berne Convention Centenary. 1986 (WIPO, 1986), p. 69.

20 Article 10(1), TRIPs Agreement. 
agreements, but can it have any effect on those Berne countries that are
neither WCT nor TRIPs members? practical importance, given the rapidly a question may be of diminishing and the WCT, but it still the rapidly increasing membership of TRIPs Article 4 simply declarative of what was already the dilemma is this - is as a consequence of a proper interpretation already the case under Berne, 'literary and artistic works' in Article 2(1)? the inclusive definition of sense of embodying a new in Article 2(1)? Or is it constitutive, in the In the case of the first, it may be asked, why hing on all Berne members? first place, as this will already have been the have such a provision in the an express provision in another convention position and to embody it in previously there was none. In the cantion will create uncertainty where limitation referred to above, namely that it cand, there is the obvious members that are also WCT and/or that it can only bind those Berne new norm binding on Berne and/or TRIPs members and cannot create a

Berne members generally.

here. Thus, Article 31(3) of the Vienna Con are only of limited assistance

of the Vienna Convention provides:

3. There shall be taken into account, together with the context: pretation of the treaty or between the parties regarding the inter-

(b) any subsequent practice in the application of its provisions; lishes the agreementication of the treaty which estab-

(c) any relevant rules of the parties regarding its interpretation; between the parties.'

Accordingly, it is possible that a subsequent agreement between the parties as to the interpretation of a particular provision, such as Article 2(1) of declaring an interpretation acceptablaratory or constitutive sense in effectively amending Article $2(1)$ se all members or, alternatively, in the list of examples of literary 2 so as to include computer programs In either case, a country that became a me works that appears there. subsequent agreement would be bound to prot of Berne after such a as literary works qua its newly assumed to protect computer programs obvious hurdle here is that it seems clear obligations under Berne. The would have to be between all current Berne the subsequent agreement either effect - and this clearly was nerne members before it could have either at the time it was signed at the Diplomatic with respect to the WCT, 1996 or subsequently, as only a fraction of Bertic Conference in December members of the WCT. In the case of the TRIP members have yet become may now be much closer in that it is possible that there will soon be an almost completely common membership between Berne and TRIPs, with the consequence that it will be possible to regard Article 10(1) of TRIPs as representing a subsequent agreement between Berne members.

The other possibility is provided by Article 31(3)(b) of Vienna, namely that Article 4 of the WCT and Article 10(1) of TRIPs are simply declarative of the position now applying with respect to the status of computer programs as a matter of the subsequent practice of Berne members. 'State practice' may not require express unanimity as between member states on the issue in question, but it would seem necessary at least that there is no dissent to the practice in question. If this is so, then it may be that the interpretation and application of the treaty provision in question can be changed as a result of this practice, with the further consequence that this interpretation and application will become binding on new members of the convention as well as upon those that may not previously have adopted it in express terms but have not previously opposed it. If this is the case with the protection of computer software, then Article 4 of the WCT and Article 10(1) of TRIPs can have no more than a declarative effect vis-à-vis what has now happened to Berne as a matter of crystallized subsequent state practice.

\section{Concluding comments}

Treaty interpretation is often a dry subject, but the purpose of this essay has been to highlight the continuing relevance in this regard of an 'ancient text' (Berne) in relation to the contemporary framework of international copyright relations. Berne is now, for better or worse, the base on which important later agreements are founded, and the way in which incorporated provisions and declaratory statements are to be interpreted are now matters of great importance to national legislators and international bodies. The present essay has therefore sought to illustrate some of these matters. 


\section{University Library}

\section{- M M I N E R VA A gateway to Melbourne's research publications}

Minerva Access is the Institutional Repository of The University of Melbourne

Author/s:

RICKETSON, S

Title:

The Berne Convention: The continued relevance of an ancient text

Date:

2004

Citation:

RICKETSON, S. (2004). The Berne Convention: The continued relevance of an ancient text. VAVER, D (Ed.). BENTLY, L (Ed.). Intellectual property in the new millennium: Essays in honour of William R Cornish, (1), pp.217-233. Cambridge University Press.

Persistent Link:

http://hdl.handle.net/11343/25394 